\title{
Macrophage-induced Glomerular Fibrin Deposition in Experimental Glomerulonephritis in the Rabbit
}

\author{
S. R. Holdsworth and P. G. Tipping \\ Department of Medicine, Prince Henry's Hospital, Monash University, Melbourne 3004, Australia
}

\begin{abstract}
Glomerular fibrin deposition is important in the pathogenesis of renal failure and crescent formation in glomerulonephritis. The mechanisms of glomerular fibrin deposition are unknown. The current studies explored the role of macrophages in this process. Methods were developed for measuring glomerular fibrin deposition and glomerular procoagulant activity in a passive model of the autologous phase of antiglomerular basement membrane antibody-induced glomerulonephritis in rabbits. Significant fibrin deposition was observed to be associated with glomerular macrophage accumulation. Leukocyte ablation with mustine hydrochloride prevented both glomerular macrophage accumulation and fibrin deposition without affecting the coagulation system or the deposition of disease-inducing antibodies and complement. Repletion with mononuclear inflammatory cells produced significant fibrin deposition. To examine the role of tissue injury per se in glomerular fibrin deposition, a macrophage-independent model of glomerular injury (heterologous phase glomerulonephritis) was also studied. Although a similar degree of glomerular injury occurred, there was no significant fibrin deposition. This suggests that macrophages, rather than injury alone, are responsible for fibrin deposition. Lysates of isolated glomeruli containing macrophages demonstrated greatly enhanced procoagulant activity compared with lysates of glomeruli without macrophages. Thus macrophages appear to be directly responsible for glomerular fibrin deposition in antiglomerular basement membrane antibody-induced glomerulonephritis, and this appears to be due to their ability to express procoagulant activity rather than their propensity to cause glomerular injury.
\end{abstract}

\section{Introduction}

Glomerular fibrin deposition (GFD) ${ }^{1}$ is a prominent feature of the most aggressive forms of glomerulonephritis $(\mathrm{GN})(1,2)$. Similarly GFD is found in experimental GN whether injury is induced by the deposition of antiglomerular basement membrane $(\mathrm{GBM})$ antibodies $(3,4)$ or immune complexes $(5,6)$. In

Address correspondence to Dr. Holdsworth. 1985.

Received for publication 16 October 1984 and in revised form 2 July

1. Abbreviations used in this paper: $\mathrm{F} / \mathrm{G}$, microgram of fibrin per 1,000 glomeruli; GBM, glomerular basement membrane; GFD, glomerular fibrin deposition; glom, glomerulus; GN, glomerulonephritis; IF, immunofluorescence; KFA, kidney-fixing antibody; macs, macrophages; PAGBMGN, passive autologous anti-GBM antibody-induced GN; PCA, procoagulant activity; PT, prothrombin time; PTTK, partial thromboplastin time with kaolin; SBT, skin bleeding time.

J. Clin. Invest.

(C) The American Society for Clinical Investigation, Inc.

$0021-9738 / 85 / 10 / 1367 / 08 \quad \$ 1.00$

Volume 76, October 1985, 1367-1374 these experimental studies, fibrin deposition was associated with the development of crescentic GN and renal failure. The significance of this deposition is highlighted by observing the protective effect of defibrination. A number of studies have shown that defibrination with Ancrod (7-10) was associated with protection from renal failure and crescent formation. Pharmacological impairment of fibrinolysis has been shown to augment GFD and renal impairment in human (11) and animal studies $(12,13)$.

The mechanism of GFD is not clear. Recent observations have shown prominent macrophage accumulation within glomeruli of patients with proliferative and crescentic GN (14-16). These are the types of GN in which fibrin deposition is most evident $(1,2)$. In experimental $\mathrm{GN}$, glomerular macrophage accumulation has also been shown to be associated with GFD ( 3 , $4,6,10)$. Macrophages have been shown to be potent triggers for fibrin deposition in inflammation, via their expression of procoagulant activity (PCA) (17-21), which activates the extrinsic pathway of the coagulation cascade. This may play an important role in fibrin deposition in GN.

The current studies sought to investigate the role of macrophages in GFD in an experimental model of GN. Techniques were developed for measuring GFD and the PCA of lysed isolated glomeruli. The effects of leukocyte depletion and mononuclear leukocyte repletion on GFD and glomerular PCA were assessed.

\section{Methods}

\section{Antibodies}

Sheep anti-rabbit GBM antibody was prepared by repeated immunization of a sheep with purified particulate rabbit GBM in Freund's complete adjuvant as previously described (3). The sheep serum was extensively absorbed against rabbit serum, platelets, leukocytes, and erythrocytes and administered as a globulin fraction. This antibody was administered at a dose shown to bind a mean of $73.6 \pm 10.5 \mu \mathrm{g}$ of specific kidney-fixing antibody (KFA) per gram wet weight of kidney, by the paired label technique (22).

The passive autologous rabbit anti-sheep globulin serum was obtained by the repeated immunization of rabbits with purified sheep gamma globulin. When rabbits had developed a high titer of antibody as measured by passive hemagglutination assay, the animals were bled out, their plasma was pooled, and a globulin fraction was prepared by precipitation with $50 \%$ ammonium sulfate. This single pool of rabbit anti-sheep globulin was used in all subsequent experiments involving passive autologous antibody administration.

The specific glomerular binding of both the heterologous and passively administered autologous antibodies in normal and mustine hydrochloride-treated animals was quantitated over the duration of the disease using the paired labeled technique described by Salant et al. (23).

\section{Histological assessment}

Kidney tissue was fixed in Bouin's fixative and stained with periodic acid-Schiff reagent to assess light microscopic appearances. Glomerular neutrophil counts were determined on a minimum of 20 equatorially sectioned glomeruli per rabbit and the results are expressed as the mean 
number of neutrophils per glomerular cross section. Tissue for immunofluorescence (IF) was frozen immediately in liquid nitrogen, then stored at $-70^{\circ} \mathrm{C} .8-\mu \mathrm{m}$ cryostat cut sections were stained with goat anti-rabbit complement, anti-rabbit fibrin, anti-rabbit IgG, and anti-sheep IgG antisera (Research Plus Laboratories, Bayonne, NJ). Normal kidney tissues were included as controls.

\section{Proteinuria}

Rabbits were housed in metabolic cages that allowed collection of the final 24-h urine sample. Protein concentrations were determined by a turbidity assay (24). Light transmission (541 nm wavelength) was measured using a light spectrophotometer (Varian Techtron Pty. Ltd., Mulgrave, Victoria, Australia) $15 \mathrm{~min}$ after addition of $3 \mathrm{vol}$ of $3 \%$ sulfosalicylic acid to 1 vol of each urine sample. Values were calculated from a standard curve derived from bovine serum albumin standards.

\section{Assessment of glomerular macrophages}

The glomerular cell culture technique was used to determine the number of macrophages in each individual glomerulus (25). Glomeruli were isolated from aseptically removed renal cortex and cultured individually in drops of culture medium (Eagle's minimal essential medium; Flow Laboratories, Melbourne, Australia) containing 10\% fetal calf serum (Flow Laboratories). After $3 \mathrm{~d}$, the cellular outgrowths were assessed under phase-contrast microscopy and the number of macrophages was recorded. Previous studies have shown this method of assessment to correlate with the presence of cells demonstrated to be macrophages by their light, phase, cine, and electron microscopic appearances as well as by their histochemical profiles, phagocytic behavior, and presence of Fc receptors (3), and to correlate with the quantitation of macrophages by histocytochemical techniques $(6,26)$. The results represent the mean of the macrophage counts from at least 12 glomeruli per animal.

\section{Quantitation of glomerular fibrin}

A technique was developed to measure the quantity of fibrin accumulating in glomeruli over a standardized time period. Rabbit fibrinogen (Sigma Chemical Co., St. Louis, MO) was radiolabeled with ${ }^{125}$ I by the chloramine $\mathrm{T}$ method and extensively dialyzed against phosphate-buffered saline. The ${ }^{125} \mathrm{I}$ activity was determined to be $97 \%$ protein bound after precipitation with trichloroacetic acid. $2 \mathrm{~h}$ after intravenous administration of ${ }^{125}$ I fibrinogen to normal rabbits, $87 \%$ of plasma radioactivity was clottable by the addition of thrombin. ${ }^{125} \mathrm{I}$ radioactivity disappeared from the plasma with an initial half-life of $15.5 \mathrm{~h}$, and then maintained a half-life of $40 \mathrm{~h}$. These results are consistent with previous studies employing labeled fibrinogen (27). ${ }^{125}$ I fibrinogen was injected intravenously as a tracer dose to each rabbit $15 \mathrm{~h}$ before the conclusion of each experiment, when the animals were killed. Plasma was taken $15 \mathrm{~min}$ after injection and at the end of the experiment to determine the specific activity of fibrinogen within the circulation at these two times. The kidneys were removed at the end of the experiment and glomeruli were isolated as previously described $(3,4,25) .{ }^{125}$ I activity was determined on aliquots of 10,000 glomeruli, and the amount of deposited fibrinogen was calculated using the specific activity of the plasma fibrinogen at the end of the experiment and taking into account the percentage of injected radioactivity that was coagulated by the addition of thrombin. The results are expressed as micrograms of fibrin per 1,000 glomeruli (F/G).

\section{Assessment of rabbit coagulation}

Fibrinogen estimation. Blood was collected for measurement of fibrinogen into $3.8 \%$ sodium citrate anticoagulant and the plasma was stored at $-70^{\circ} \mathrm{C}$. Using a sheep anti-rabbit fibrinogen antiserum (Research Plus Laboratories), fibrinogen was measured in an immunoturbidometric assay using a centrifugal analyzer (Centrichem 400; Union Carbide Corp., Rye, NY). The antibody was shown to produce a single immunoprecipitin line when reacted against normal rabbit plasma by the Ouchterlony double-immunodiffusion technique. No immunoprecipitin line was produced when the antiserum was reacted against normal rabbit serum. The antiserum was used at a dilution of 1:16 in 5\% polyethylenelgycol and $0.8 \%$ saline. Standards of known concentration were prepared from rabbit fibrinogen, and the standard and test samples were diluted to $1: 16$ in $0.9 \%$ saline. The absorbance of light ( $340 \mathrm{~nm}$ wavelength) by the reaction mixture was maximum after $5 \mathrm{~min}$ reaction time. Absorbance vs. fibrinogen concentration was plotted between 0 and $10 \mathrm{~g} /$ liter and the unknown samples were calculated from this plot.

Skin bleeding times (SBT). The hair overlying the marginal vein of the rabbit's ear was shaved using a scapel blade, and the vein was pierced in three sites using a 21-gauge needle. The average of the time for the last two puncture sites to stop bleeding was taken as the SBT. Excess blood was removed every $5 \mathrm{~s}$ using an absorbant tissue while waiting for the cessation of bleeding.

Prothrombin time (PT). Blood was collected in $3.8 \%$ sodium citrate anticoagulant and centrifuged at room temperature to obtain plateletpoor plasma. $100 \mu \mathrm{l}$ of plasma was warmed at $37^{\circ} \mathrm{C}$ for $3 \mathrm{~min}$ in a 75 $\times 12 \mathrm{~mm}$ glass test tube. $200 \mu \mathrm{l}$ of prewarmed rabbit thromboplastin standard (Simplastin; General Diagnostics, Div. of Warner-Lambert Co., Morris Plains, NJ) was forcibly added and the clotting time was determined by the manual tilt method. All assays were performed in duplicate within $3 \mathrm{~h}$ of blood collection.

Partial thromboplastin time with kaolin (PTTK). Plasma was collected as for PTs. $100 \mu \mathrm{l}$ of plasma and $100 \mu \mathrm{l}$ of PTTK reagent (Pathrombin, Behring-Werke AG, Marburg/Lahn, FRG) were prewarmd together at $37^{\circ} \mathrm{C}$ in $75 \times 12 \mathrm{~mm}$ glass tubes for exactly $2 \mathrm{~min} .100 \mu \mathrm{l}$ of $0.025 \mathrm{M}$ calcium chloride was then added forcibly and the clotting time was determined by the manual tilt method on duplicate samples.

Blood platelet counts. Citrated blood was centrifuged at $200 \mathrm{rpm}$ for $20 \mathrm{~min}$. Plasma $(6.6 \mu \mathrm{l})$ was diluted in $20 \mathrm{ml}$ of Isoton diluent (Coulter Electronics, Harpenden, Herts, England) and counted on an automatic platelet counter (Thrombocounter C; Coulter Electronics).

Circulating leukocyte count. $20 \mu \mathrm{l}$ of blood was collected and diluted in $3 \%$ acetic acid using a microcollection system (Unopette; BectonDickinson \& Co., Rutherford, NJ). The number of cells was enumerated in a modified Neubauer hemocytometer, and the total circulating leukocyte count was calculated.

Assessment of PCA in isolated glomeruli. Glomeruli were isolated by the same technique used for glomerular cell culture. Preparations containing 10,000 glomeruli $/ \mathrm{ml}$ of culture medium were stored at $-20^{\circ} \mathrm{C}$ and frozen and thawed twice before assay. The lysates of these isolated glomeruli were assayed for PCA using a standard one-stage clotting assay previously described by Schwartz and Edgington (28) and Rothberger et al. (29). $100 \mu \mathrm{l}$ of lysate was prewarmed for $3 \mathrm{~min}$ with $100 \mu \mathrm{l}$ of 0.025 $M$ calcium chloride in a $75 \times 12 \mathrm{~mm}$ glass tube at $37^{\circ} \mathrm{C} .100 \mu \mathrm{l}$ of freshly prepared, citrated, platelet-poor rabbit plasma (prewarmed to $37^{\circ} \mathrm{C}$ ) was added, and the clotting time was determined by the manual tilt method. All assays were performed in duplicate at dilutions of $1: 1,1: 10$, and 1 : 100. PCA was derived by comparison of clotting times with a standard curve using rabbit thromboplastin (Simplastin). $100 \mu$ l of thromboplastin standard was considered to have $1,000 \mathrm{mU}$ of activity, and the standard curve was linear on a $\log / \log$ plot of activity vs. clotting time over a range from 0.1 to $1,000 \mathrm{mU}$. The PCA was expressed as milliunits per 1,000 glomeruli. The requirement for Factor VIII in the expression of glomerular PCA was assessed by testing the capacity of glomerular lysates to coagulate Factor VIII-deficient human plasma in comparison to normal human plasma (Dade Diagnostics Inc., Aguada, Puerto Rico) in this assay.

\section{Experimental design}

LEUKOCYTE DEPLETION STUDIES. Four groups, each of nine rabbits between 1.8 and $2.4 \mathrm{~kg}$ in weight, were used in these studies.

Group A: passive autologous anti-GBM antibody induced $G N$ $(P A G B M G N)$. This disease was initiated by the intravenous injection of sheep anti-rabbit GBM globulin ( $74 \mu \mathrm{g} / \mathrm{g} \mathrm{KFA}, 30 \mathrm{mg} / \mathrm{kg}$ body wt) followed by three further intravenous injections of passive autologous rabbit anti-sheep globulin $(120 \mathrm{mg} / \mathrm{kg})$ at intervals of $12 \mathrm{~h}$ between each dose. Animals were killed $5 \mathrm{~h}$ after the last dose of passive antibody.

Group B: mustine hydrochloride-treated PAGBMGN. These animals were treated with mustine hydrochloride (Boots Pure Drug Co., Ltd., Nottingham, England) at an initial dose of $1.7 \mathrm{mg} / \mathrm{kg}$ i.v. followed $36 \mathrm{~h}$ 
later by a second dose of $1 \mathrm{mg} / \mathrm{kg}$ at the time of initiation of PAGBMGN disease as previously described (30).

Group C: heterologous passive anti-GBM GN. This disease was initiated by the intravenous injection of sheep anti-rabbit GBM globulin (74 $\mu \mathrm{g} / \mathrm{g} \mathrm{KFA}$ ). Rabbits were killed $24 \mathrm{~h}$ later. To assess the effects of heterologous sheep anti-rabbit GBM globulin on GFD over $41 \mathrm{~h}$, six rabbits were repeatedly injected intravenously with $74 \mathrm{mg} / \mathrm{g} \mathrm{KFA}$ with $12 \mathrm{~h}$ between each dose, and the fibrin deposition in the last $15 \mathrm{~h}$ was assessed.

Group D: controls. These animals received normal sheep globulin 30 $\mathrm{mg} / \mathrm{kg}$ i.v. followed by passive autologous rabbit anti-sheep globulin as described for group A.

In all animals, a coagulation profile was obtained on the day of sacrifice. Urine was collected over the $24 \mathrm{~h}$ before sacrifice for the estimation of proteinuria. At the time of sacrifice, kidney tissue was obtained to assess histological and IF appearances, glomerular macrophage accumulation, F/G, and glomerular PCA. All results are expressed as mean \pm SEM, and statistical significance was assessed by the $t$ test.

MONONUCLEAR INFLAMMATORY CELL RECONSTITUTION STUDIES. An abbreviated model of PAGBMGN was used to study the effect of mononuclear inflammatory cell repletion following mustine hydrochloride treatment. This was done to avoid anticipated technical difficulties in reconstituting mononuclear cells over the $41 \mathrm{~h}$ of injury in the previous model. A recently reported model, with a shorter duration of injury in which reconstitution studies have successfully reproduced macrophage-mediated glomerular injury, was employed (31).

This disease was induced by an identical dose ( $74 \mu \mathrm{g} / \mathrm{g} \mathrm{KFA})$ of the same anti-GBM antibody used in the initial studies. This was followed $15 \mathrm{~h}$ later by three doses of passive autologous antibody $(120 \mathrm{mg} / \mathrm{kg})$ at four hourly intervals, and the rabbits were killed $7 \mathrm{~h}$ after the last injection. GFD, glomerular macrophage accumulation, and PCA were assessed as described in the initial experiment.

Mononuclear cells were harvested from the peritoneal cavities of rabbits injected with $3 \%$ thioglycolate (Becton-Dickinson \& Co., Cockeysville, MD) $3 \mathrm{~d}$ earlier. Blood mononuclear cells were also obtained from these rabbits after isolation by centrifugation on Lympho-paque (Nyegaard \& Co., Oslo, Norway) according to the method of Bøyum (32). Cell preparations were pooled, and then smeared and demonstrated to be $>99 \%$ mononuclear cells by Wright's stain, before administration. Cells were administered in two intravenous doses, each of $10^{8}$ cells, 30 min after the second and third doses of passive autologous antibody.

Three groups of rabbits were compared: group 1, composed of untreated rabbits developing PAGBMGN $(n=7)$; group 2, composed of rabbits depleted of leukocytes by mustine hydrochloride, as previously described, and then given PAGBMGN-initiating antibodies $(n=7)$; and group 3, composed of rabbits treated with mustine hydrochloride, given PAGBMGN-initiating antibodies, and reconstituted with mononuclear inflammatory cells. $(n=6)$.

DEMONSTRATION OF FIBRIN DEPOSITION AROUND GLOMERULAR MACROPHAGES IN CULTURE. Glomeruli from rabbits with PAGBMGN were cultured on glass slides as previously described. Normal rabbit plasma was added to Eagle's minimum essential medium at a 1:10 dilution along with calcium chloride at a final concentration of $0.025 \mathrm{M}$. The mixture was allowed to react with the cultured cells for $2 \mathrm{~min}$, and then the cells were washed three times in $0.9 \%$ saline containing $10 \mathrm{U} / \mathrm{ml}$ heparin and fixed in formalin/acetone fixative. The slides were stained for nonspecific esterase by the method of Yam et al. (33) to demonstrate tissue macrophages by their characteristic cytoplasmic staining. The presence of fibrin was demonstrated by staining with fluoresceinated goat anti-rabbit fibrinogen antiserum (Research Plus Laboratories) at a dilution of 1:5. Controls included cultures treated in a similar manner without recalcification of the added plasma.

\section{Results}

\section{Leukocyte depletion studies}

The parameters of glomerular injury and fibrin deposition are shown in Tables I and II and discussed below.
GROUP A: PAGBMGN. Histology. These rabbits all developed a diffuse endocapillary proliferative GN. Mononuclear cells appeared consistently and uniformly within capillary lumens. Glomerular crescents were not present. A mean of $0.3 \pm 0.04$ neutrophils was observed per glomerular cross section.

Immunofluorescent appearances. Glomeruli from these rabbits showed strong linear immunofluorescent staining for rabbit IgG, C3, and sheep IgG. Immunofluorescent staining for fibrin showed prominent GFD with a speckled pattern in mesangia and capillary loops in all glomeruli (Fig. 1).

Proteinuria. All rabbits developed proteinuria $(1,253 \pm 376$ $\mathrm{mg} / 24 \mathrm{~h}$ ). The 24-h urinary protein output of control rabbits was $13.5 \pm 1.2 \mathrm{mg} / 24 \mathrm{~h}$.

Glomerular macrophage accumulation. Macrophages consistently accumulated in the glomeruli of rabbits with PAGBMGN (26.2 \pm 4.8 macrophages [macs] per glomerulus [glom]), but were only occasionally present in control rabbits ( $0.3 \pm 0.2 \mathrm{macs} / \mathrm{glom})$.

Quantitation of glomerular fibrin $(F / G)$. Fibrin deposition was detected in all the rabbits with PAGBMGN. After the 15-h measurement period, the mean glomerular fibrin $(F / G)$ was $44.7 \pm 15.0 \mu \mathrm{g}$ fibrin $/ 10^{3}$ glomeruli and was significantly greater than in control rabbits $\left(2.2 \pm 0.6 \mu \mathrm{g}\right.$ fibrin $/ 10^{3}$ glomeruli, $P<0.005$ ). The decline in the specific activity of plasma fibrinogen of rabbits with PAGBMGN was $58.1 \pm 4.6 \%$ over the period of the study. This was not significantly different from the decline in specific activity of plasma fibrinogen in control rabbits $(64.2 \pm 4.8 \%)$.

GROUP B: MUSTINE HYDROCHLORIDE-TREATED PAGBMGN. Administration of mustine hydrochloride produced severe leukopenia in all treated rabbits $(390 \pm 75$ leukocytes/ $\mathrm{mm}^{3}$ ). Their leukocyte numbers were significantly reduced when compared with control rabbits $\left(9,680 \pm 364\right.$ leukocytes $/ \mathrm{mm}^{3}, P$ $<0.005)$ and with untreated rabbits with PAGBMGN $\left(18,380 \pm 976\right.$ leukocytes $\left./ \mathrm{mm}^{3}, P<0.005\right)$. Mustine hydrochloride treatment did not significantly alter the binding of heterologous or autologous anti-GBM antibody. The specific glomerular binding of heterologous antibody was $20.3 \pm 1.7 \mu \mathrm{g} / 10^{4}$ glomeruli in treated rabbits and $19.9 \pm 1.6 \mu \mathrm{g} / 10^{4}$ in untreated rabbits. Specific glomerular binding of autologous antibody was $1.92 \pm 0.32 \mu \mathrm{g} / 10^{4}$ glomeruli in treated rabbits and $1.90 \pm 0.11$ $\mu \mathrm{g} / 10^{4}$ glomeruli in untreated rabbits developing PAGBMGN.

Histology. The histological appearances of GN were considerably attenuated in these rabbits compared with untreated rabbits with PAGBMGN. There were only occasional mononuclear cells observed within the capillary lumens of the glomeruli.

Immunofluorescent appearances. The rabbits treated with mustine hydrochloride were found to have a linear deposition of rabbit IgG, C3, and sheep IgG in the same pattern and extent as the untreated rabbits with PAGBMGN. Fibrin was not detectable by IF in the glomeruli of the treated rabbits.

Proteinuria. Rabbits treated with mustine hydrochloride developed proteinuria $(729 \pm 249 \mathrm{mg} / 24 \mathrm{~h})$; however, this was significantly less than in the untreated group $(P<0.05)$.

Glomerular macrophage accumulation. Treatment with mustine hydrochloride did not entirely prevent glomerular macrophage accumulation; however, their numbers were significantly reduced ( $2.1 \pm 0.9$ macs/glom) compared with the untreated rabbits $(26.2 \pm 4.8 \mathrm{macs} / \mathrm{glom}, P<0.005)$.

Quantitation of glomerular fibrin $(F / G)$. The amount of fibrin within the glomeruli of mustine hydrochloride-treated animals was $2.6 \pm 0.5 \mu \mathrm{g}$ fibrin $/ 10^{3}$ glomeruli. Fibrin accumulation was 


\begin{tabular}{lcccc}
\hline & Control & PAGBMGN & $\begin{array}{l}\text { Mustine-treated } \\
\text { PAGBMGN }\end{array}$ & $\begin{array}{l}\text { Heterologous phase } \\
\text { anti-GBM GN }\end{array}$ \\
\hline Proteinuria $(\mathrm{mg} / 24 \mathrm{~h}$ ) & $13.5 \pm 1.2$ & $1,253 \pm 376$ & $792 \pm 249$ & $1,190 \pm 665$ \\
Glomerular macrophages $($ macs $/$ glom $)$ & $0.3 \pm 0.2$ & $26.2 \pm 4.8$ & $2.1 \pm 0.9$ & $7.9 \pm 3.3$ \\
GFD $\left(\mu \mathrm{g}\right.$ fibrin/10 ${ }^{3}$ gloms) & $2.2 \pm 0.6$ & $44.7 \pm 15.0$ & $2.6 \pm 0.5$ & $3.7 \pm 1.4$ \\
\hline
\end{tabular}

significantly less than for untreated rabbits with PAGBMGN $\left(44.7 \pm 15.0 \mu \mathrm{g}\right.$ fibrin $/ 10^{3}$ glomeruli, $\left.P<0.005\right)$ and not statistically different from control rabbits $\left(2.2 \pm 0.6 \mu \mathrm{g}\right.$ fibrin $/ 10^{3}$ glomeruli).

GROUP C: HETEROLOGOUS PHASE ANTI-GBM GN. Histology. Rabbits given heterologous anti-GBM globulin alone rapidly developed a proliferative $\mathrm{GN}$ with neutrophils as the predominant infiltrating cell (mean $6.2 \pm 2.6$ neutrophils per glomerular cross section).

Immunofluorescent appearance. Glomeruli from these rabbits showed linear staining for sheep IgG and rabbit C3. Staining for rabbit IgG and rabbit fibrin, however, was not detected.

Proteinuria. These rabbits all developed heavy proteinuria $(1,190 \pm 665 \mathrm{mg} / 24 \mathrm{~h})$ that was similar in extent to that of the rabbits with PAGBMGN $(1,253 \pm 376 \mathrm{mg} / 24 \mathrm{~h})$.

Glomerular macrophage accumulation. A minor macrophage accumulation was observed in the glomeruli of rabbits developing heterologous anti-GBM antibody-induced injury (7.9 \pm 3.3 macs/ glom), although this was significantly less than that observed in rabbits with PAGBMGN $(P<0.005)$.

Quantitation of glomerular fibrin $(F / G)$. Fibrin deposition within the glomeruli of the rabbits with heterologous phase antiGBM GN was $3.7 \pm 1.4 \mu \mathrm{g}$ fibrin $/ 10^{3}$ glomeruli. This was not significantly greater than for control or mustine hydrochloridetreated rabbits. After $41 \mathrm{~h}$ of heterologous phase injury, glomerular fibrin deposition did not change significantly $(F / G$, $3.8 \pm 1.1 \mu \mathrm{g}$ fibrin $/ 10^{3}$ glomeruli).

COAGULATION PROFILE (TABLE III). There were no significant differences in the PTs or PTTKs of any of the experimental groups. Similar platelet counts were observed in rabbits with PAGBMGN $\left(313,000 \pm 63,000\right.$ platelets $\left./ \mathrm{mm}^{3}\right)$, heterologous anti-GBM GN $\left(354,000 \pm 73,000\right.$ platelets $\left./ \mathrm{mm}^{3}\right)$, and in control rabbits $\left(292,000 \pm 56,000\right.$ platelets $\left./ \mathrm{mm}^{3}\right)$. Rabbits treated with mustine hydrochloride developed mild thrombocytopenia $\left(138,000 \pm 22,000\right.$ platelets $\left./ \mathrm{mm}^{3}, P<0.05\right)$. The SBTs were not significantly different in any of these groups.

Plasma fibrinogen levels increased significantly in rabbits with PAGBMGN $(9.3 \pm 1.1 \mathrm{~g} /$ liter $)$ and in rabbits with heterologous phase anti-GBM GN (6.1 $\pm 0.5 \mathrm{~g} /$ liter) compared with

Table II. Immunofluorescent Demonstration of Heterologous Antibody (Sheep IgG), Autologous Antibody (Rabbit IgG), and Complement (C3)

\begin{tabular}{lllll}
\hline & Control & PAGBMGN & $\begin{array}{l}\text { Mustine-treated } \\
\text { PAGBMGN }\end{array}$ & $\begin{array}{l}\text { Heterologous phase } \\
\text { anti-GBM GN }\end{array}$ \\
\hline Sheep IgG & 0 & +++ & +++ & +++ \\
Rabbit IgG & 0 & +++ & +++ & 0 \\
Rabbit C3 & 0 & +++ & +++ & +++ \\
Rabbit fibrin & 0 & +++ & 0 & 0 to + \\
& & & & \\
\hline
\end{tabular}

control rabbits ( $5.0 \pm 0.3 \mathrm{~g} /$ liter, $P<0.025$ for both groups). There was no significant change in the plasma fibrinogen level in rabbits with mustine hydrochloride-treated PAGBMGN $(4.3 \pm 0.4 \mathrm{~g} /$ liter) compared with control rabbits.

GLOMERULAR PCA (FIG. 2). The glomerular lysates from the rabbits with PAGBMGN were able to accelerate coagulation of normal rabbit plasma and Factor VIII-deficient human plasma. Culture medium alone was unable to accelerate coagulation in comparison with normal saline in this system. The PCA present in glomerular lysates produced a dose-response curve that was parallel to the dose-response curve for standard rabbit thromboplastin (Fig. 2). This curve was used to calculate the amount of glomerular PCA. The amount of glomerular PCA (compared with Simplastin standard) in lysates of glomeruli from rabbits with PAGBMGN was $425 \pm 100 \mathrm{mU} / 10^{3}$ glomeruli. This was significantly greater than PCA in glomeruli of control rabbits (30.7 $\pm 10.5 \mathrm{mU} / 10^{3}$ glomeruli, $\left.P<0.005\right)$. Glomerular PCA in rabbits treated with mustine hydrochloride was significantly less than in the untreated rabbits $\left(39.5 \pm 15 \mathrm{mU} / 10^{3}\right.$ glomeruli, $P$ $<0.005$ ) but was not significantly different from PCA levels in control rabbits.

The participation of Factor VIII in coagulation induced by glomerular PCA was assessed by comparing its potency in normal human plasma and Factor VIII-deficient human plasma. The potency of PCA from glomerular lysates of rabbits with PAGBMGN was the same in Factor VIII-deficient and normal human plasma.

\section{Mononuclear inflammatory cell repletion studies}

Glomerular fibrin deposition in the abbreviated model of PAGBMGN (Table IV) was $5.4 \pm 0.9 \mu \mathrm{g}$ fibrin $/ 10^{3}$ gloms. This was accompanied by glomerular macrophage accumulation (59.9 $\pm 13.0 \mathrm{macs} / \mathrm{glom})$, and PCA was detected in the glomerular lysates (171 $\pm 48 \mathrm{mU} / 10^{3}$ gloms).

Treatment with mustine hydrochloride blocked glomerular macrophage accumulation (2.7 $\pm 1.4 \mathrm{macs} / \mathrm{glom})$ and significantly reduced GFD $\left(1.6 \pm 0.5 \mu \mathrm{g}\right.$ fibrin $/ 10^{3}$ gloms, $\left.P<0.05\right)$. $P C A$ of glomerular lysates was also significantly reduced $(56 \pm 11$ $\mathrm{mU} / 10^{3}$ gloms, $P<0.05$ ).

Repletion of mustine hydrochloride-treated rabbits with mononuclear inflammatory cells was associated with an increase in glomerular macrophage accumulation (18.5 \pm 12 macs/glom). This resulted in a significant increase in GFD (3.5 $\pm 0.6 \mu \mathrm{g}$ fibrin/ $10^{3}$ gloms, $\left.P<0.025\right)$ and augmentation of PCA in glomerular lysates $\left(100 \pm 20 \mathrm{mU} / 10^{3}\right.$ gloms, $\left.P<0.05\right)$.

\section{Demonstration of fibrin deposition by glomerular macrophages in culture (Fig. 3)}

Fibrin was distinguished by IF (Fig. $3 \mathrm{~B}$ ) on the surface of esterase-positive cells (Fig. $3 A$ ) in the cellular outgrowths of cultured glomeruli from rabbits with PAGBMGN. No fibrin was associated with the intrinsic glomerular cells distinguished by 


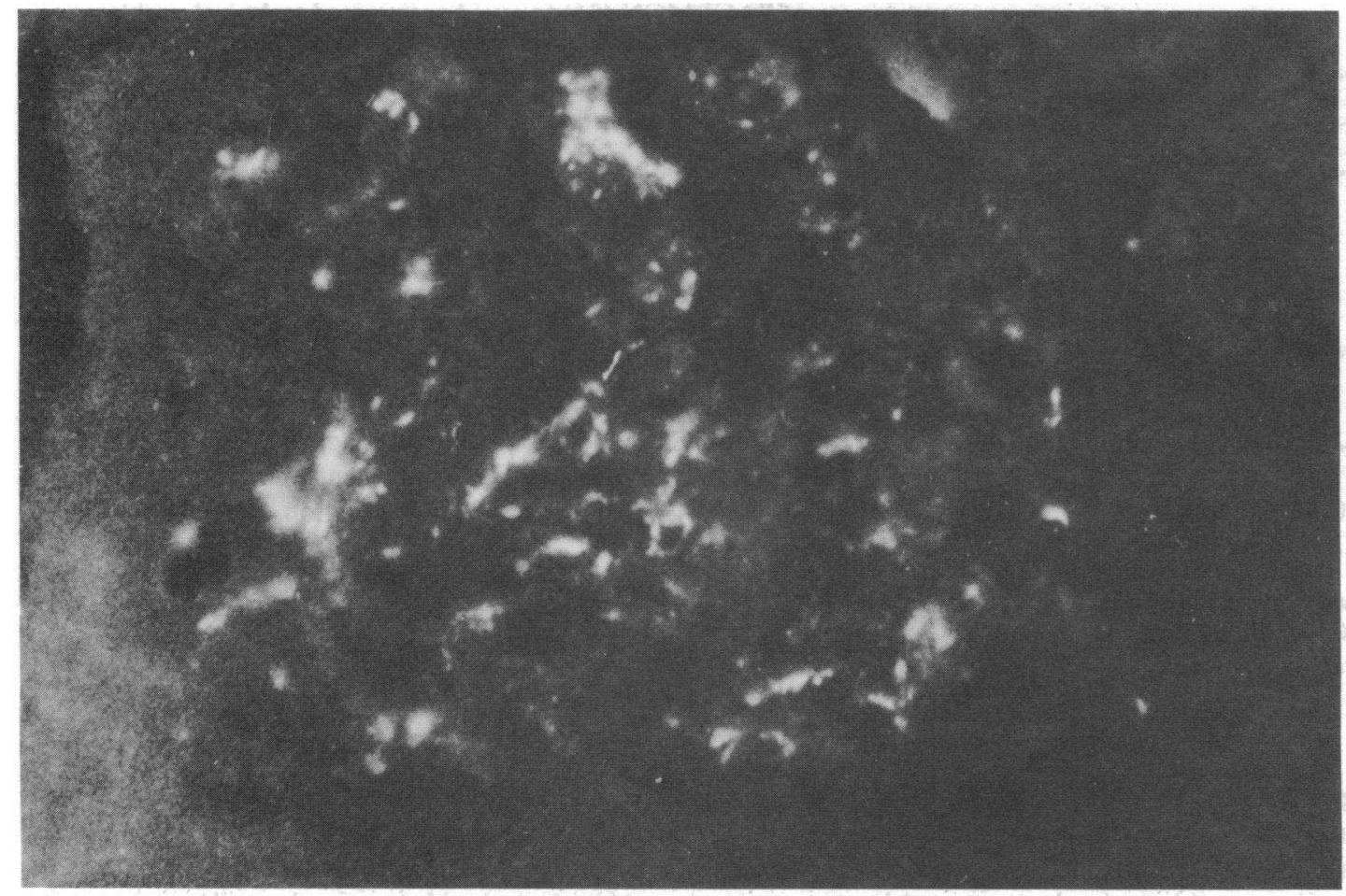

Figure 1. A photomicrograph of a glomerulus from a rabbit with PAGBMGN, demonstrating fibrin by direct IF using fluoresceinated goat antirabbit fibrinogen antiserum. Original $\times 320$.

their characteristic morphology under phase-contrast microscopy $(3,14)$. Control cultures (glomerular outgrowths from rabbits with PAGBMGN treated in a similar manner but without recalcification of added plasma) showed no evidence of fibrin deposition.

\section{Discussion}

The autologous phase of anti-GBM antibody-induced GN is an extensively studied model of glomerular injury in which GFD is associated with the development of crescentic GN and renal failure $(2-4,8-10,34,35)$. This model was used as the basis for our studies; however, the disease was induced by the passive administration of autologous antibody so that subsequent leukocyte depletion experiments could be performed without altering the glomerular deposition of this disease-inducing antibody (as previously reported in reference 30 ). This was confirmed by measurements of specific glomerular bound antibody (both heterologous and autologous) by the paired labeled technique (23). As in the active autologous disease, glomerular injury in this passive model was associated with glomerular macrophage ac- cumulation and fibrin deposition. In this model, there was insufficient time for glomerular crescent formation.

To compare GFDs between groups of rabbits, radioactively labeled fibrinogen (which retained its coagulability) was used to quantitate fibrin deposition. This technique measures the quantity of fibrin accumulating in glomeruli over the period of study. This was considered to be of more relevance than studying the kinetics of glomerular fibrin turnover, as it is the net accumulation of fibrin that is of pathological significance. The results obtained with this method correlated with the immunofluorescent demonstration of glomerular fibrin.

Mustine hydrochloride-treated rabbits developed severe leukopenia, thus preventing glomerular macrophage accumulation and GFD. These animals did not exhibit any functional alteration of their coagulation parameters, which may have accounted for this effect. A mild thrombocytopenia did occur; however, platelet numbers were not reduced to levels known to interfere with coagulation (36). Previous studies $(37,38)$ have shown that specific platelet depletion (to much lower levels than observed in the current studies) does not reduce GFD in PAGBMGN. Electron microscopic studies have failed to dem-

Table III. Coagulation Parameters

\begin{tabular}{lcccc}
\hline & Control & PAGBMGN & $\begin{array}{l}\text { Mustine-treated } \\
\text { PAGBMGN }\end{array}$ & $\begin{array}{l}\text { Heterologous phase } \\
\text { anti-GBM GN }\end{array}$ \\
\hline PT $(s)$ & $6.9 \pm 0.3$ & $6.7 \pm 0.4$ & $7.4 \pm 0.3$ & $6.8 \pm 0.1$ \\
PTTK $(s)$ & $36.8 \pm 7: 3$ & $50.9 \pm 9.5$ & $47.6 \pm 6.4$ & $35.4 \pm 0.9$ \\
SBT $(s)$ & $71.0 \pm 9.2$ & $68.9 \pm 7.2$ & $81.0 \pm 8.5$ & $77.7 \pm 9.7$ \\
Platelets $\left(\mathrm{mm}^{-3}\right)$ & $292,000 \pm 56,000$ & $313,000 \pm 63,000$ & $138,000 \pm 22,000$ & $354,000 \pm 73,000$ \\
Plasma fibrinogen $(\mathrm{g} /$ liter $)$ & $5.0 \pm 0.3$ & $9.3 \pm 1.1$ & $4.3 \pm 0.4$ & $6.1 \pm 0.5$ \\
& & & & \\
\hline
\end{tabular}




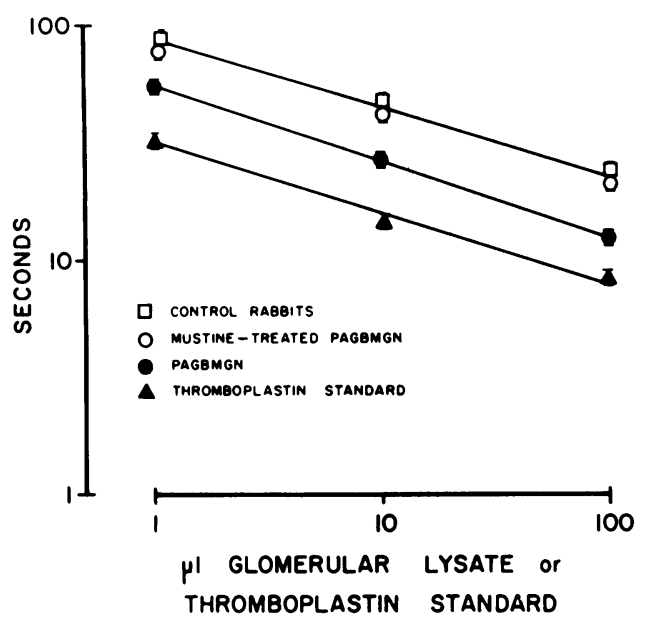

Figure 2. The dose-response curve for PCA in lysates of glomeruli isolated from rabbits with PAGBMGN, mustine hydrochloride-treated PAGBMGN, and normal rabbits. The curve for rabbit thromboplastin is also shown.

onstrate any significant platelet accumulation in this lesion (39). Despite normal coagulation parameters, these rabbits did not develop GFD. The levels of GFD were similar to those of control animals, and glomerular fibrin could not be demonstrated by IF. These observations demonstrate that the deposition of disease-inducing antibodies and associated complement activation in the absence of circulating leukocytes does not initiate GFD. Therefore fibrin deposition is dependent on the accumulation of leukocytes within glomeruli.

Previous studies (30) have shown that macrophages are the leukocytes responsible for injury in PAGBMGN. In our study, macrophages were again found to be the predominant infiltrating cell with only a minimal neutrophil contribution. This strongly suggests that macrophages are the infiltrating leukocytes responsible for GFD. Further evidence that neutrophils are not involved in GFD comes from studies of the heterologous phase of anti-GBM GN. In this model, neutrophils are the predominant infiltrating leukocytes and are known to induce injury (40). However, despite the much greater neutrophil presence in this model, GFD was not observed. Therefore in PAGBMGN it would be unlikely that the smaller numbers of neutrophils would be significantly contributing to GFD, and this suggests that macrophages are the leukocytes responsible for initiating GFD in this disease.

More direct evidence of the pivotal role of macrophages in GFD is provided by the mononuclear inflammatory cell repletion studies. These studies were performed in an abbreviated model

Table IV. Mononuclear Inflammatory Cell Repletion Studies in Abbreviated PAGBMGN

\begin{tabular}{llll}
\hline & PAGBMGN & $\begin{array}{l}\text { Mustine-treated } \\
\text { PAGBMGN }\end{array}$ & $\begin{array}{l}\text { Repleted } \\
\text { PAGBMGN } \\
\text { after mustine }\end{array}$ \\
\hline $\begin{array}{c}\text { Glomerular macrophages } \\
(\text { macs } / \text { glom })\end{array}$ & $59.9 \pm 13.0$ & $2.7 \pm 1.4$ & $18.5 \pm 12.0$ \\
$\begin{array}{c}\text { GFD }\left(\mu \mathrm{g} \text { fibrin } / 10^{3}\right. \\
\text { gloms })\end{array}$ & $5.4 \pm 0.9$ & $1.6 \pm 0.5$ & $3.5 \pm 0.6$ \\
$\begin{array}{c}\text { Glomerular PCA } \\
\left(\mathrm{mU} / 10^{3} \text { gloms }\right)\end{array}$ & $171 \pm 48$ & $56 \pm 11$ & $100 \pm 20$ \\
\hline
\end{tabular}

of PAGBMGN (31) to avoid anticipated technical problems associated with reproducing injury that developed over a 41-h period in the initial model. This abbreviated model has been previously used to demonstrate glomerular injury after macrophage repletion.

These studies again demonstrated significant reduction of glomerular macrophages and GFD after treatment with mustine hydrochloride. Repletion with mononuclear inflammatory cells resulted in partial but significant restoration of GFD. PCA in glomerular lysates was also significantly increased. These studies clearly confirm the capacity of mononuclear inflammatory cells to induce GFD. The fact that only partial repletion of macrophages, GFD, and PCA occurred was not unexpected as previous studies have shown that with both neutrophil (41) and macrophage (31) repletion, complete restoration of the active GN is not possible.

Macrophages may directly activate fibrin formation by the expression of PCA (17-21) or indirectly by their capacity to cause tissue injury. Macrophage-damaged glomerular cells may release tissue thromboplastins, and collagenlike fragments of damaged GBM may induce contact activation of the intrinsic coagulation pathway.

Studies of the model of heterologous anti-GBM antibody-induced GN provide evidence that GBM injury is not responsible for GFD. In this model and in PAGBMGN, similar degrees of proteinuria and histological evidence of endocapillary injury were observed. Significant GFD, however, was only observed in PAGBMGN, which strongly suggests that GBM damage alone is insufficient to account for GFD.

Another approach to studying the mechanisms of GFD was to assess the potential of lysates of glomeruli to induce coagulation in vitro. Techniques similar to those used in studies of macrophage PCA were employed $(28,29)$. Lysates of glomeruli from mustine hydrochloride-treated rabbits given disease-initiating antibodies had similar levels of PCA to normal controls. Glomerular lysates from rabbits with PAGBMGN had signifcantly increased levels of PCA. This increase in PCA could only be accounted for by the presence of glomerular macrophages.

Studies by Hoyer et al. (42) assessing renal tissue from patients with GN and prominent fibrin deposition failed to demonstrate the presence of Factor VIII. This finding suggested that the intrinsic coagulation pathway was not involved in fibrin deposition in human GN. Macrophage PCA is capable of activating the extrinsic coagulation cascade and does not require Factor VIII $(18,29)$. The PCA of glomerular lysates from rabbits with PAGBMGN was similar when tested in human Factor VIIIdeficient and normal human plasma. Thus glomerular PCA appears to activate the extrinsic coagulation pathway, as does macrophage PCA. Macrophage-induced GFD via PCA would thus explain the observations of Hoyer et al. (42).

Further proof of the macrophage origin of glomerular PCA came from tissue culture studies of isolated glomeruli. Both intrinsic glomerular cells and macrophages were prominent in the outgrowths from glomeruli isolated from rabbits with PAGBMGN. Only macrophages (identified by esterase positivity) were capable of inducing fibrin deposition from recalcified citrated plasma.

Many components of the immune response can stimulate the expression of macrophage PCA. These include immunoglobulin $(43,44)$, immune complexes $(44)$, complement $(45$, $46)$, and lymphocytes $(28,47)$. As most of these components are simultaneously present in glomeruli after antibody deposi- 


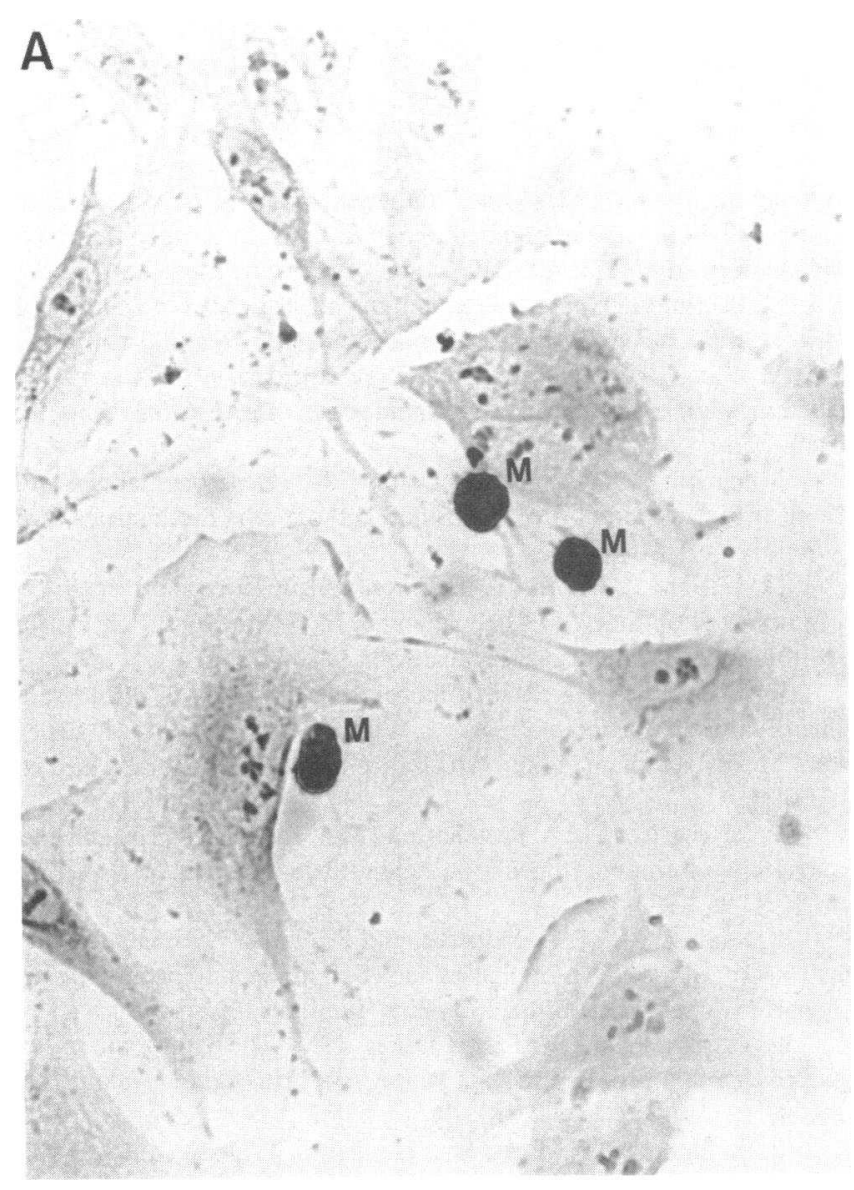

Figure 3. $(A)$ A photomicrograph of the cellular outgrowths from a cultured glomerulus from a rabbit with PAGBMGN stained for nonspecific esterase to identify macrophages $(\mathrm{M})$. The large spreading unstained cells are typical intrinsic glomerular cells. Original $\times 160$.

tion, the relative importance of individual components could not be discerned.

In conclusion, these studies show that glomerular macrophage accumulation in experimental $\mathrm{GN}$ is associated with measurable fibrin deposition. The abrogation of this GFD in association with macrophage depletion, the induction of GFD by mononuclear cell repletion, and the demonstration of Factor VIII-independent PCA in glomerular lysates strongly suggest that macrophages are directly responsible for GFD in the model studied. Further, it is likely that macrophages observed in human GN can account for any associated GFD.

\section{Acknowledgments}

The skilled technical assistance of Ms. M. Frommer, Ms. L. Worthington, and Ms. R. Johnston is gratefully acknowledged.

This work was supported by grants from the National Health and Medical Research Council (NH \& MRC) of Australia and the Australian Kidney Foundation. Dr. Tipping is a recipient of an NH \& MRC postgraduate research scholarship.

\section{References}

1. Kincaid-Smith, P. 1972. Coagulation and renal disease. Kidney Int. 2:183-190.

2. Vassalli, P., and R. T. McCluskey. 1971. The pathogenic role of

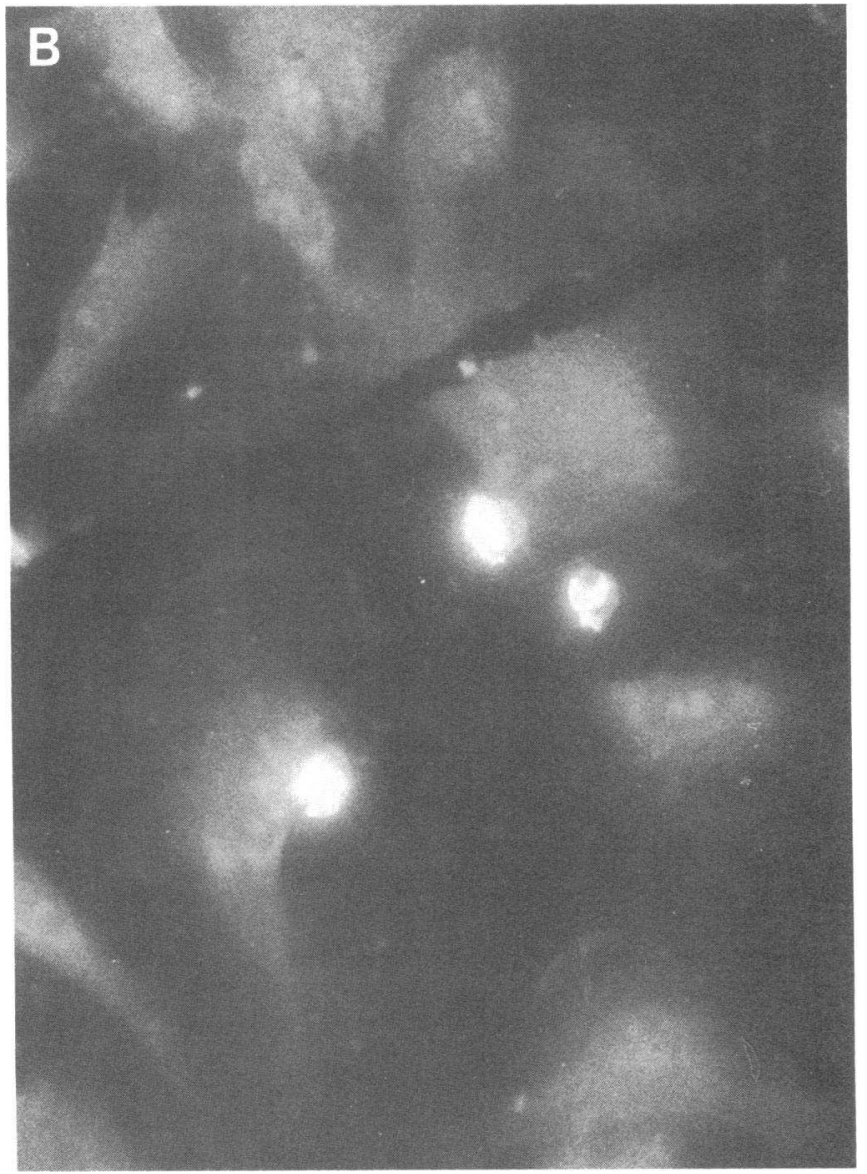

(B) A photomicrograph of the same cellular outgrowths demonstrating fibrin staining on macrophages by direct IF using fluoresceinated goat anti-rabbit fibrinogen antiserum. Original $\times 160$.

the coagulation process in glomerular diseases of immunological origin. Adv. Nephrol. 1:47-63.

3. Holdsworth, S. R., N. M. Thomson, E. R. Glasgow, J. R. Dowling, and R. C. Atkins. 1978. Tissue culture of isolated glomeruli in experimental crescentic glomerulonephritis. J. Exp. Med. 147:98-109.

4. Thomson, N. M., S. R. Holdsworth, E. F. Glasgow, and R. C. Atkins. 1979. The macrophage in the development of experimental crescentic glomerulonephritis. Am. J. Pathol. 94:233-240.

5. Wilson, C. B., and F. J. Dixon. 1971. Quantitation of acute and chronic serum sickness in the rabbit. J. Exp. Med. 134(Suppl.):7S-8S.

6. Holdsworth, S. R., T. J. Neale, and C. B. Wilson. 1980. The participation of macrophages and monocytes in experimental immune complex glomerulonephritis. Clin. Immunol. Immunopathol. 15:510524.

7. Thomson, N. M., I. J. Simpson, D. J. Evans, and D. K. Peters. 1975. Defibrination with Ancrod in experimental chronic immune complex nephritis. Clin. Exp. Immunol. 20:527-535.

8. Naish, P. F., D. J. Evans, and D. K. Peters. 1975. The effects of defibrination with Ancrod in experimental allergic glomerular injury. Clin. Exp. Immunol. 20:303-309.

9. Thomson, N. M., J. Moran, I. J. Simpson, and D. K. Peters. 1976. Defibrination with ancrod in nephrotoxic nephritis in rabbits. Kidney Int. 10:343-347.

10. Holdsworth, S. R., N. M. Thomson, E. F. Glasgow, and R. C. Atkins. 1979. The effect of defibrination on macrophage participation in rabbit nephrotoxic nephritis: studies using glomerular culture and electron microscopy. Clin. Exp. Immunol. 37:38-44.

11. Charytan, C., and O. Purtilo. 1969. Glomerular capillary throm- 
bosis and acute renal failure after epsilon-amino caproic acid therapy. N. Engl. J. Med. 280:1102-1104.

12. Watanabe, T., and K. Tanaka. 1976. The role of coagulation and fibrinolysis in the development of rabbit Masugi nephritis. Acta Pathol. Jpn. 26:147-165.

13. Clarke, B. E., K. N. Ham, J. D. Tange, and G. B. Ryan. 1983. Macrophages and glomerular crescent formation. Studies with rat nephrotoxic nephritis. Pathology. 15:75-81.

14. Atkins, R. C., S. R. Holdsworth, E. F. Glasgow, and F. E. Matthews. 1976. The macrophage in human rapidly progressive glomerulonephritis. Lancet. I:830-832.

15. Monga, G., G. Mazzucco, G. Barbiano di Belgiojoso, and G. Busnach. 1981. Monocyte infiltration and glomerular hypercellularity in human acute and persistent glomerulonephritis. Lab. Invest. 44:381387.

16. Magil, A. B., and L. D. Wadsworth. 1981. Monocytes in human glomerulonephritis. An electron microscopic study. Lab. Invest. 45:77-81.

17. Lerner, R. G., R. Goldstein, and G. Cummings. 1971. Stimulation of leukocyte thromboplastic activity by endotoxin. Proc. Soc Exp. Biol. Med. 138:145-148.

18. Edwards, R., F. R. Rickles, and A. M. Bobrove. 1979. Mononuclear cell tissue factor. Cell of origin and requirements for activation. Blood. 54:359-370.

19. Maier, R. V., and R. J. Ulevitch. 1981. The induction of a unique procoagulant activity in rabbit hepatic macrophages by bacterial lipopolysaccharides. J. Immunol. 127:1596-1600.

20. Garg, S. K., and J. Niemetz. 1973. Tissue factor of normal and leukemic cells. Blood. 42:729-735.

21. Hogg, N. 1983. Human monocytes are associated with the formation of fibrin. J. Exp. Med. 157:473-485.

22. Wilson, C. B., F. J. Dixon, J. B. Fortner, and J. Cerilli. 1971. Glomerular basement membrane-reactive antibody in anti-lymphocytic globulin. J. Clin. Invest. 50:1525-1535.

23. Salant, D. J., C. Darby, and W. G. Couser. 1980. Experimental membranous glomerulonephritis in rats. Quantitative studies of glomerular immune deposit formation in isolated glomeruli and whole animals. J. Clin. Invest. 66:71-81.

24. Kingsbury, F. B., C. P. Clark, G. Williams, and A. L. Post. 1926. The rapid determination of albumin in urine. J. Lab. Clin. Med. 11: 981-989.

25. Holdsworth, S. R., E. F. Glasgow, N. M. Thomson, and R. C. Atkins. 1978. Tissue culture of isolated human glomeruli. Pathology. 10:59-66.

26. Tipping, P. G., T. J. Neale, and S. R. Holdsworth. 1985. T lymphocyte participation in antibody induced experimental glomerulonephritis. Kidney Int. 27:530-537.

27. Regoeczi, E., J. Gergely, and A. S. McFarlane. 1966. In vivo effects of Agkistrodon rhodostoma venom. Studies with fibrinogen ${ }^{131} \mathrm{I}$ J. Clin. Invest. 45:1202-1212.

28. Schwartz, B. S., and T. S. Edgington. 1981. Immune complexinduced human monocyte procoagulant activity. I. A rapid undirectional lymphocyte instructed pathway. J. Exp. Med. 154:892-906.

29. Rothberger, H., F. B. Dove, T. K. Lee, M. P. McGee, and B. Kardon. 1983. Procoagulant activity of lymphocyte-macrophage populations in rabbits: selective increases in marrow, blood and spleen cells during Schwartzman reactions. Blood. 61:712-717.
30. Holdsworth, S. R., T. J. Neale, and C. B. Wilson. 1981. Abrogation of macrophage-dependent injury in experimental glomerulonephritis in the rabbit. Use of an antimacrophage serum. J. Clin. Invest. 58:686698

31. Holdsworth, S. R., and T. J. Neale. 1984. Macrophage induced glomerular injury. Cell transfer studies in passive autologous antiglomerular basement membrane antibody initiated experimental glomerulonephritis. Lab. Invest. 51:172-180.

32. Bøyum, A. 1968. Isolation of mononuclear cells and granulocytes from human blood. Scand. J. Clin. Lab. Invest. 21(Suppl. 97):77-89.

33. Yam, L. T., C. Y. Li, and W. H. Crosby. 1971. Cytochemical identification of monocytes and granulocytes. Am. J. Clin. Pathol. 55: 283-290.

34. Unanue, E. R., and F. J. Dixon. 1967. Experimental glomerulonephritis: immunological events and pathogenetic mechanisms. $A d v$ Immunol. 6:1-90.

35. Wilson, C. B., and F. J. Dixon. 1981. The renal response to immunological injury. In The Kidney. B. M. Brenner and F. J. Rector, editors. W. B. Saunders Co., Philadelphia. 1237-1354.

36. Williams, W. J. 1976. Clinical manifestations of disorders of hemostasis. In Haematology. W. J. Williams, E. Beutler, A. J. Erslev, and M. A. Lichtman, editors. McGraw-Hill Inc., New York. Third ed. 69-72.

37. Lavelle, K. J., B. A. Ransdell, and S. A. Kleit. 1976. The influence of selective thrombocytopenia on nephrotoxic nephritis. J. Lab. Clin. Med. 87:967-975.

38. Sindrey, M., T. L. Marshall, and P. Naish. 1979. Quantitative assessment of the effects of platelet depletion in the autologous phase of nephrotoxic serum nephritis. Clin. Exp. Immunol. 36:90-96.

39. Vassalli, P., and R. T. McCluskey. 1964. The pathogenic role of the coagulation process in rabbit Masugi nephritis. Am. J. Pathol. 45: 653-677.

40. Cochrane, C. G., E. R. Unanue, and F. J. Dixon. 1965. A role of polymorphonuclear leukocytes and complement in nephrotoxic nephritis. J. Exp. Med. 122:99-116.

41. Henson, P. M. 1972. Pathological mechanisms in neutrophil mediated injury. Am. J. Pathol. 68:593-612.

42. Hoyer, J. R., A. F. Michael, and L. W. Hoyer. 1974. Immunofluorescent localization of antihemophilic factor antigen and fibrinogen in human renal disease. J. Clin. Invest. 53:1375-1384.

43. Rothberger, H., T. K. Lee, J. Dunne, and T. S. Zimmerman. 1982. Increases of leukocyte tissue factor activity stimulated by red cells sensitized with human blood group alloantibodies. Thromb. Res. 27 537-547.

44. Rothberger, H., T. S. Zimmerman, H. L. Spiegelberg, and J. H. Vaughan. 1977. Leukocyte procoagulant activity. Enhancement of production in vitro by $\mathrm{IgG}$ and antigen-antibody complexes. J. Clin. Invest. 59:549-557.

45. Prydz, H., A. C. Allison, and H. U. Schorlemmer. 1977. Further link between complement activation and blood coagulation. Nature (Lond.). 270:173-174.

46. Muhlfelder, T. W., J. Niemetz, D. Kreuttzer, D. Beebe, P. Ward, and S. I. Rosenfield. 1979. C5 chemotactic fragment induces leukocyte production of tissue factor activity. J. Clin. Invest. 63:147-150.

47. Edwards, R. L., and F. R. Rickles. 1980 . The role of human T cells (and T cell products) for monocyte tissue factor generation. J. Immunol. 125:606-609. 